\title{
Iron in airway macrophages and infective exacerbations of chronic obstructive pulmonary disease
}

\author{
Terence Ho ${ }^{1,2^{*}}$, Matthew Nichols ${ }^{3}$, Gayatri Nair ${ }^{1}$, Katherine Radford ${ }^{4}$, Melanie Kjarsgaard ${ }^{4}$, \\ Chynna Huang ${ }^{4}$, Anurag Bhalla ${ }^{1,2}$, Nicola Lavigne ${ }^{4}$, Manali Mukherjee ${ }^{1}$, Michael Surette ${ }^{1}$, Joseph Macri ${ }^{5}$ and \\ Parameswaran Nair ${ }^{1,2}$
}

\begin{abstract}
Background: Excess pulmonary iron has been implicated in the pathogenesis of lung disease, including asthma and COPD. An association between higher iron content in sputum macrophages and infective exacerbations of COPD has previously been demonstrated.
\end{abstract}

Objectives: To assess the mechanisms of pulmonary macrophage iron sequestration, test the effect of macrophage iron-loading on cellular immune function, and prospectively determine if sputum hemosiderin index can predict infectious exacerbations of COPD.

Methods: Intra- and extracellular iron was measured in cell-line-derived and in freshly isolated sputum macrophages under various experimental conditions including treatment with exogenous IL- 6 and hepcidin. Bacterial uptake and killing were compared in the presence or absence of iron-loading. A prospective cohort of COPD patients with defined sputum hemosiderin indices were monitored to determine the annual rate of severe infectious exacerbations.

Results: Gene expression studies suggest that airway macrophages have the requisite apparatus of the hepcidinferroportin axis. IL-6 and hepcidin play roles in pulmonary iron sequestration, though IL-6 appears to exert its effect via a hepcidin-independent mechanism. Iron-loaded macrophages had reduced uptake of COPD-relevant organisms and were associated with higher growth rates. Infectious exacerbations were predicted by sputum hemosiderin index ( $\beta$ $=0.035, p=0.035$ ).

Conclusions: We demonstrate in-vitro and population-level evidence that excess iron in pulmonary macrophages may contribute to recurrent airway infection in COPD. Specifically, IL-6-dependent iron sequestration by sputum macrophages may result in immune cell dysfunction and ultimately lead to increased frequency of infective exacerbation.

Keywords: COPD, Exacerbation, Sputum, Infection, Iron

*Correspondence: hot4@mcmaster.ca

${ }^{2}$ Firestone Institute for Respiratory Health, St. Joseph's Healthcare Hamilton, 50 Charlton Avenue East, Hamilton, ON L8N 4A6, Canada

Full list of author information is available at the end of the article

\section{Background}

Chronic obstructive pulmonary disease (COPD) is a respiratory condition characterized by partially reversible airflow limitation and frequent exacerbations [1]. Acute exacerbations of COPD (AECOPD) are amongst the most common reason for admission to hospital [2], with infections estimated to be the underlying etiology in $50-70 \%$ of cases $[3,4]$. original author(s) and the source, provide a link to the Creative Commons licence, and indicate if changes were made. The images or other third party material in this article are included in the article's Creative Commons licence, unless indicated otherwise in a credit line to the material. If material is not included in the article's Creative Commons licence and your intended use is not permitted by statutory regulation or exceeds the permitted use, you will need to obtain permission directly from the copyright holder. To view a copy of this licence, visit http://creativecommons.org/licenses/by/4.0/. The Creative Commons Public Domain Dedication waiver (http://creativeco mmons.org/publicdomain/zero/1.0/) applies to the data made available in this article, unless otherwise stated in a credit line to the data. 
Iron is a ubiquitous element and an essential nutrient to nearly all organisms [5]. It is necessary for the generation of reactive oxygen species, which is crucial for cellular bactericidal capacity. As a growth essential nutrient, increased iron may create a favourable environment for bacterial growth and increased virulence [6]. Systemic iron regulation, which occurs primarily by cellular sequestration, has been well-described [7]. IL-6 acts on hepatocytes and macrophages to stimulate the release of hepcidin, which subsequently causes the degradation of membrane-bound ferroportin. As the only known exporter of iron, the degradation of ferroportin leads to iron being trapped intracellularly. In the respiratory tract, these mechanisms are poorly understood, with the current evidence almost exclusively from murine models $[8,9]$.

Chronic inflammation can lead to the over-accumulation of iron, best described in anemia or chronic disease in hemodialysis patients [10]. Excess iron has also been implicated in the development of chronic diseases such as atherosclerosis and Alzheimer's disease [6]. Recently, excess pulmonary iron has been shown to potentially play an important role in the pathogenesis of pulmonary fibrosis [11] and asthma [12]. Iron accumulation also appears to be important in COPD, as demonstrated by correlations between lung iron content and airflow obstruction and emphysema severity [13], and between airway iron and exacerbation [14], as well as proteomic analyses and genomewide association studies of genes of iron metabolism [15]. Murine experiments have demonstrated that chelation of free iron prevented cigarette smokeinduced emphysema in mice [15]. The mechanism by which iron could cause susceptibility to COPD is not clear, but could be related to bacterial colonisation and infection of the airways, as supported by cell-line studies of experimental iron-loading demonstrating lysosomal dysfunction and reduced bactericidal capacity [16], and improvement in bactericidal activity with chelation in murine alveolar macrophages [17]. Such experiments have not been performed with respiratory-specific human pathogens in mind, or in human airway macrophages.

We hypothesized that raised respiratory iron content in COPD will increase the susceptibility to respiratory tract infection and subsequently lead to recurrent exacerbation. Our specific objectives were to: (1) Assess the mechanisms of human pulmonary macrophage iron sequestration; (2) Test the effect of macrophage iron-loading on cellular immune function; and (3) Prospectively determine if sputum hemosiderin index can predict infectious exacerbations of COPD.

\section{Methods}

Objective 1: Mechanisms of human pulmonary macrophage iron sequestration

To address this objective, serum and sputum measurements from a clinical cohort of COPD patients (as described below), real time quantitative polymerase chain reaction (RT-qPCR) of sputum cells from select patients within the COPD cohort and healthy controls, and cell-line derived and sputum macrophage experiments from healthy controls, were pursued.

\section{Clinical cohort for prospective study}

Patients were recruited from a single-centre during an admission for AECOPD (primary diagnosis) from December 2016 to May 2018. Informed consent was obtained from all subjects. The study was approved by the Hamilton Integrated Research Ethics Board (Project $\# 1281$ ). Inclusion in the study required age $\geq 40$ years, one or more features of COPD/emphysema (airflow obstruction $\left[\mathrm{FEV}_{1} / \mathrm{FVC}<0.7\right]$, radiologic evidence of emphysema), in the setting of $\mathrm{a} \geq 10$ pack-year history of cigarette smoking. Those who required admission to the intensive care unit, were unable to produce a spontaneous sputum, or had a history of asthma or bronchiectasis of greater than mild severity radiographically [18], were excluded.

\section{Serum and sputum measurements in clinical cohort}

Serum and spontaneous or induced sputum, were collected during exacerbation and at least 8-weeks post-discharge (stable state). Sputum samples were processed as previously described [19] to yield cell-free supernatant and a cell pellet.

Iron content in the airways was measured at exacerbation and stable state by two methods: staining of sputum cells with Prussian Blue to yield a sputum macrophage hemosiderin index (SHI) and quantification of free iron in the sputum supernatant by inductively-coupled mass spectrometer (ICP-MS). For additional detail please refer to the see Additional File 1: Methods.

For planned measurement of fluid phase analytes in sputum, supernatants were supplemented with protease cocktail inhibitor (Roche ${ }^{\mathrm{TM}}$, Switzerland) and stored at $-70{ }^{\circ} \mathrm{C}$ for detecting fluid-phase analytes. IL-6 and hepcidin (R\&D Systems ${ }^{\mathrm{TM}}$, Minneapolis, MN) were measured in both serum and sputum supernatant samples by enzyme-linked immunosorbent assay (ELISA). Lower limits of detection were $9.38 \mathrm{pg} / \mathrm{mL}$ and $3.12 \mathrm{pg} /$ $\mathrm{mL}$, respectively. Both ELISAs were performed following the user's manuals with substitution of Strepavidin 
alkaline phosphatase rather than the Strepavidin horseradish peroxidase provided in the kits [20].

\section{$R N A$ extraction and $R T-q P C R$}

Messenger ribonucleic acid was isolated from frozen whole sputum cell pellets (previously stored at $-80{ }^{\circ} \mathrm{C}$ in $90 \%$ fetal calf serum [Invitrogen ${ }^{\mathrm{TM}}$, Carlsbad, CA] and $10 \%$ dimethyl sulfoxide freezing media [Sigma-Aldrich ${ }^{\mathrm{TM}}$, St. Louis, MO]) from 17 COPD subjects ( 9 with $\mathrm{SHI}<10$ and 8 with $\mathrm{SHI} \geq 10$ ), and 5 healthy controls (never smokers with no known respiratory or cardiac disease) by magnetic microbeads $\left(\mu \mathrm{MACS}^{\mathrm{TM}}\right.$ mRNA isolation kit, Miltenyi ${ }^{\mathrm{TM}}$, Bergisch Gladbach, Germany), then reversetranscribed to create complementary deoxyribonucleic acid (cDNA; $\mu \mathrm{MACS}^{\mathrm{TM}}$ cDNA kit, Miltenyi ${ }^{\mathrm{TM}}$, Bergisch Gladbach, Germany), and stored at $-80{ }^{\circ} \mathrm{C}$. Nanodrop ${ }^{\mathrm{TM}}$ One (ThermoFisher Scientific ${ }^{\mathrm{TM}}$, Waltham, MA) was used to quantify the concentration of cDNA present. The COPD patients that participated in this part of the study were recruited consecutively during study-related followup. Expression levels of human hepcidin antimicrobial peptide (HAMP) and ferroportin (SLC40A1) genes were reported relative to the GAPDH housekeeping gene. The primer sequences and additional methods are included in Additional file 1: Methods.

The difference in cycle threshold $(\Delta \mathrm{Ct})$ for each gene of interest was calculated by subtracting $\mathrm{Ct}$ for GAPDH from that of the gene of interest $\left(\triangle \mathrm{Ct}=\mathrm{Ct}_{\text {gene }}-\right.$ $\left.\mathrm{Ct}_{\mathrm{GAPDH}}\right)$. To determine the relative expression in COPD subjects, the $\Delta \mathrm{Ct}$ for the gene of interest in these subjects was compared to the average $\Delta \mathrm{Ct}$ in healthy controls by the following equation: $2^{-(\Delta \text { Ctpatient }-\Delta \text { Cthealthyaverage) }}$.

\section{Macrophage iron sequestration experiments}

THP1 cells were cultured, passaged, and differentiated into THP1-derived macrophages (TDM). TDMs were then sub-cultured with media containing $\mathrm{FeSO}_{4} 100 \mu \mathrm{M}$ and one of the experimental conditions (listed below). For further details regarding TDM differentiation and validation of cellular iron sequestration in the setting of iron-enriched media, please see Additional file 1 . The experimental conditions consisted of: recombinant human IL-6 at $50 \mathrm{ng} / \mathrm{mL}$ (Abcam ${ }^{\mathrm{TM}}$, Cambridge, UK), recombinant human hepcidin at $1 \mu \mathrm{g} / \mathrm{mL}$ (Peptides International $^{\mathrm{TM}}$, Louisville, KY), heat-inactivated $\mathrm{HI}\left(1 \times 10^{6}\right.$ bacteria in $35 \mu \mathrm{L}$ PBS; hi-HI), hi-HI with IL-6, hi-HI with hepcidin, IL-6 with hepcidin, and hi-HI with IL-6 and hepcidin. Heat inactivation of HI was achieved by incubating at $55^{\circ} \mathrm{C}$ for $10 \mathrm{~min}$. Cells were sub-cultured under these conditions for 24-h, after which the plate was centrifuged, and the supernatant aspirated and stored at $-20{ }^{\circ} \mathrm{C}$. After the supernatant was completely aspirated, each well was washed with $2 \mathrm{~mL}$ of PBS, and then incubated with $0.5 \mathrm{~mL}$ of $0.25 \%$ trypsin $\left(\right.$ Gibco $^{\mathrm{TM}}$, Gaithersburg, MD) to lift the cells. The main outcome for the TDM experiments was the intracellular iron content as measured by ICP-MS.

These experiments were completed on sputum macrophages (SM) from healthy controls (never smokers with no known respiratory or cardiac disease), with similar methods. Sputum macrophages were isolated by plastic adherence from fresh sputum cell pellets (as previously described; [9]). Post-isolation samples that contained $<85 \%$ macrophages (on hematoxylin and eosin stained cytospin slides) were discarded. Differently than TDM experiments, SM experiments included only IL-6 and hepcidin as conditions, and utilized Accutase ${ }^{\mathrm{TM}}$ (Sigma-Aldrich $^{\mathrm{TM}}$, St. Louis, MO) and cell-scraper to lift cells. Iron efflux, as determined by the difference in iron concentration of control media from that of the supernatant after 24-h of incubation (both measured by ICP-MS), was chosen as the main outcome for these SM experiments.

\section{Objective 2: The effect of iron-loading on macrophage immune function}

As described below, bacterial killing assays for TDM and SM were pursued to examine this objective.

\section{Bacterial killing assay for sputum macrophages}

Isolated sputum macrophages (by plastic adherence) from 10 different COPD cohort patients who were recruited consecutively during a period of clinical stability were diluted to a standardized concentration with $1 \times$ Hank's Balanced Salt Solution and combined with $H$. influenzae strain to achieve a multiplicity of infection of 10 and then incubated on a shaker at $200 \mathrm{rpm}$. At 1-h and $1.5-\mathrm{h}$, a $100 \mu \mathrm{L}$ aliquot was removed, centrifuged at $3000 \mathrm{rpm}$ for $4.5 \mathrm{~min}$ and then resuspended with $100 \mu \mathrm{L}$ of sterile $1 \times$ Hank's Balanced Salt Solution to remove extracellular bacteria. This solution was then serially diluted with sterile deionized water $\left(10^{-1}\right.$ to $\left.10^{-5}\right)$ to lyse the macrophages, and then $10 \mu \mathrm{L}$ plated in duplicate on the appropriate agar. Agar plates were left under the hood to dry (approximately $10 \mathrm{~min}$ ), and then incubated overnight. The next day, colony-forming units (CFU) were counted after 24-h of incubation for each dilution where possible and CFU/mL calculated. Bacterial killing after 1.5 -h incubation was determined by comparing the $\mathrm{CFU} / \mathrm{mL}$ at this time point with the $\mathrm{CFU} / \mathrm{mL}$ at $1-\mathrm{h}$.

\section{Bacterial uptake and killing assays for THP1-derived macrophages}

TDM were sub-cultured in control media (RPMI 1640 with L-glutamine [2 $\mathrm{mM}], 10 \%$ fetal calf serum and Phorbol 12-myristate-13-acetate of $100 \mathrm{nM}$ ) or iron-enriched 
media (supplemented with $\mathrm{FeSO}_{4}$ at $250 \mu \mathrm{M}$ ) for $48 \mathrm{~h}$ and then lifted as previously described. Viable TDMs were combined with bacteria (grown to $\mathrm{OD}_{600}$ of 0.5 ) at a multiplicity of infection of 10 and then incubated on a shaker at $200 \mathrm{rpm}$. The experiment then proceeded similar to SM bacterial uptake and killing assays, but including time points of $1-\mathrm{h}, 1.5-\mathrm{h}, 2-\mathrm{h}, 3-\mathrm{h}$, and $5-\mathrm{h}$. The main outcome of this experiment was the bacterial uptake of iron-loaded TDM, which was determined by comparing the $\mathrm{CFU} / \mathrm{mL}$ to the control TDM at the 1-h time point.

\section{Objective 3: Sputum hemosiderin index as a predictor of infectious AECOPD}

The previously described prospective clinical cohort was utilized to address this objective.

\section{Prospective COPD cohort}

Participants in the prospective cohort were monitored for 1-year for severe (requiring hospital admission) infectious exacerbations (primary outcome). As mentioned above, airway iron indices (SHI and ICP-MS) were measured at the time of exacerbation and after discharge during a stable state (see Additional file 1: Methods for further detail). At the time of severe AECOPD, an underlying infectious etiology was investigated by respiratory virus polymerase chain reaction by nasopharyngeal swab (RV-PCR), and spontaneous sputum culture and differential and cell count. An infectious exacerbation was defined as $\geq 1$ of: positive respiratory virus RV-PCR, positive sputum culture, and/or total sputum neutrophil count $\geq 12$ million cells/g. AECOPD was confirmed by a change in sputum appearance, sputum volume, or increased dyspnea by the admitting service [21].

\section{Statistics}

For the prospective cohort data, descriptive statistics are presented as mean $\pm \mathrm{SD}$ for parametric data and median (IQR) for non-parametric data. Linear regression and Spearman correlations were used to determine the associations between variables. Comparisons between two groups were accomplished by t-test (parametric) or Mann-Whitney test (non-parametric). In instances where paired testing could have been applied but sputum data were missing, we chose to analyze in an unpaired fashion. Comparisons between multiple groups were performed by ANOVA (with Dunnett's multiple comparisons test) for parametric data and Kruskal-Wallis tests (with Dunn's multiple comparisons test) for nonparametric data. Group comparisons of grouped data were accomplished by Friedman test. $\mathrm{p}<0.05$ was considered statistically significant. All analyses were performed using either SPSS 23.00. IBM Corporation, Armonk, NY, USA, or GraphPad Prism version 8.0.0 for Mac OS X,
GraphPad Software, San Diego, California USA, www. graphpad.com. Using previously reported annualized COPD exacerbation rates $(\mu=1.53, \sigma=1.05)$ [22], to detect an absolute difference in infective exacerbation frequency of $50 \%$, we estimated that we would require 46 subjects total assuming a beta of 0.2 and alpha of 0.05 (one-sided test).

\section{Results}

\section{Prospective clinical cohort}

Fifty-six subjects consented to participate in the study, of which 49 completed the 1-year monitoring period. Seven subjects were lost to follow-up due to death $(n=4)$, being unreachable by telephone $(n=2)$, and withdrawing due to a new diagnosis of cancer $(n=1)$. Baseline characteristics are summarized in Table 1. Parameters related to systemic iron and echocardiogram results are summarized in Additional file 2: Table S1.

\section{Mechanisms of macrophage iron sequestration}

Within the patient cohort, the sputum hemosiderin index collected during clinical stability was significantly higher than during AECOPD (median 14[4.3,31]\% vs 2.5[1.0,8.8], $\mathrm{p}=0.0001$, Mann-Whitney test; Fig. 1a). The levels of unbound iron demonstrated the opposite with lower values during clinical stability than at AECOPD $(2.6 \pm 0.73$ vs $3.1 \pm 0.82 \mu \mathrm{M}, \mathrm{p}=0.015$, unpaired $\mathrm{t}$-test; Fig. 1b; Table 2). Neither serum or sputum IL-6 changed significantly at AECOPD compared to follow-up. On the other hand, serum hepcidin was significantly higher

Table 1 Baseline characteristics of prospective clinical cohort

\begin{tabular}{|c|c|}
\hline Demographics & Value \\
\hline Number of participants & 49 \\
\hline Age (years) & $67 \pm 9$ \\
\hline Male/Female & $32 / 17$ \\
\hline Caucasian (\%) & 94 \\
\hline \multicolumn{2}{|l|}{ COPD-related variable } \\
\hline LAMA use $(n, \%)$ & $45(91.8 \%)$ \\
\hline Inhaled corticosteroid use $(n, \%)$ & $43(87.5 \%)$ \\
\hline LABA use $(n, \%)$ & $40(81.6 \%)$ \\
\hline Current smoker (\%) & 57.1 \\
\hline Smoking history (pack-years) & $50(39,63)$ \\
\hline Radiographic emphysema (\%) & 90.6 \\
\hline Home $\mathrm{O}_{2}(\%)$ & 38.3 \\
\hline $\mathrm{FEV}_{1}(\mathrm{~L})$ & $1.1 \pm 0.47$ \\
\hline FEV $_{1}$ (\%Predicted) & $41 \pm 18$ \\
\hline Self-reported AECOPD in last 1-year & $2(0,4)$ \\
\hline Self-reported Admission for AECOPD in last 1-year & $0(0,1)$ \\
\hline
\end{tabular}

LAMA long-acting muscarinic antagonist, FEV1 forced expiratory volume in 1-s, $A E C O P D$ acute exacerbation of chronic obstructive pulmonary disease 

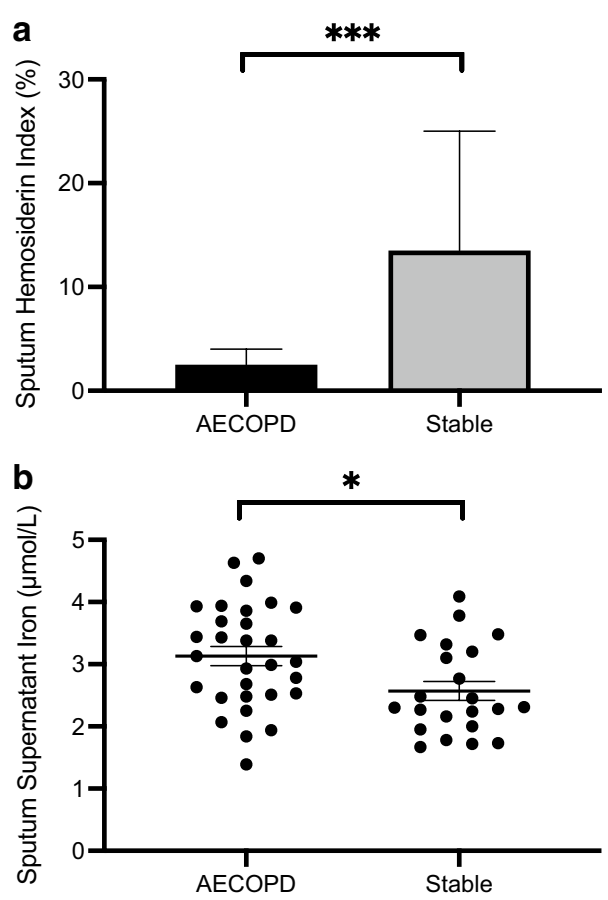

Fig. 1 a Sputum hemosiderin index in subjects during acute exacerbation and clinical stability. ${ }^{* *} p<0.001$. Data shown as median (IQR). AECOPD acute exacerbation of chronic obstructive pulmonary disease. $\mathbf{b}$ Sputum supernatant iron concentration in subjects during acute exacerbation and clinical stability. Data shown as mean \pm SEM. ${ }^{*} p<0.05$. AECOPD acute exacerbation of chronic obstructive pulmonary disease

during AECOPD than during follow-up while sputum hepcidin did not demonstrate such a difference (Summarized in Table 2). SHI at follow-up was correlated with sputum IL-6 $(r=0.37, p=0.045$, Spearman; Linear regression shown in see Additional file 3: Fig. S1a) and serum IL-6 $(r=0.31, p=0.086$, Spearman; Linear regression shown in see Additional file 4: Fig. S1b) measured during AECOPD. Neither SHI during AECOPD or during follow-up were correlated with serum or sputum hepcidin. To examine the contribution of cigarette smoking to sputum iron, SHI and supernatant iron levels were compared stratified based on smoker's inclusions in the sputum (None, Few, Moderate, Many), and smoking status (current versus ex-smoker). The analysis of SHI was limited by only three patients with at least moderate smoker's inclusions and a viable SHI at exacerbation. Otherwise, when post-AECOPD SHI or supernatant iron during AECOPD or post-AECOPD were stratified by smoker's inclusions or smoking status, no associations were seen.

In sputum cells of COPD patients, HAMP expression was increased relative to healthy controls with no difference demonstrated between patients with high and low intracellular iron $(1.40[0.94,4.30]$ vs. $2.34[1.70,8.00]$ fold difference, $p=0.09$, Mann-Whitney test, Fig. 2a). On the other hand, relative to healthy controls, SLC40A1 expression in COPD patients was elevated in the high intracellular iron group and reduced in those with low intracellular iron, with significantly greater expression in the high versus low group $(5.38[1.42,12.10]$ vs. 0.22 $[0.03,0.51], p=0.0006$, Mann-Whitney test, Fig. 2b). There were no differences in age or sex between healthy controls, COPD patients with low SHI, and COPD patients with high SHI. No differences in smoking status and pack-year exposure were noted between low and high SHI groups (See Additional file 5: Table S2).

In experiments with SM from healthy controls $(\mathrm{n}=7)$, there was a significant reduction in supernatant iron concentration when subculturing with IL-6 (median $-17.2[-28.0,-11.5] \%, \mathrm{p}=0.032$ ) and hepcidin (median $-16.6[-21.1,-9.9] \%, p=0.003$, all by Dunn's multiple comparisons test) compared with control, reflective of iron sequestration (Fig. 3). In TDM experiments $(\mathrm{n}=4)$, sub-culturing in media with IL-6 (median $16.0[12.4,18.0] \mu \mathrm{M}, \mathrm{p}=0.014$ ), hepcidin (median 17.2 [15.2,18.8] $\mu \mathrm{M}, \mathrm{p}=0.0028$ ), and IL-6 with hepcidin (median $17.6[9.71,20.9] \mu \mathrm{M}, \mathrm{p}=0.014$, all by Dunn's multiple comparisons test; see Additional file 6: Fig. S2) led to increased intracellular iron content (as measured by ICP-MS) compared to control (median

Table 2 Measures of airway intra- and extra-cellular iron, and potential iron-regulatory proteins

\begin{tabular}{llll}
\hline Serum/sputum variables & AECOPD & Post-AECOPD & p-value \\
\hline Sputum hemosiderin index $(\%)$ & $2.5(1.0,8.8)$ & $14.0(4.3,31.0)$ & 0.0001 \\
Sputum free iron $(\mu \mathrm{M})$ & $3.1 \pm 0.8$ & $2.6 \pm 0.7$ & 0.015 \\
Serum IL-6 $(\mathrm{pg} / \mathrm{mL})$ & $2.8(2.3,36.6)$ & $3.4(2.2,10.7)$ & 0.94 \\
Sputum IL-6 $(\mathrm{pg} / \mathrm{mL})$ & $63.4(11.5,211.0)$ & $111.0(34.2,198.0)$ & 0.19 \\
Serum Hepcidin $(\mathrm{ng} / \mathrm{mL})$ & $77.8(18.9,111.4)$ & $24.8(4.6,79.6)$ & 0.01 \\
Sputum Hepcidin $(\mathrm{pg} / \mathrm{mL})$ & $31.1(8.0,71.8)$ & $15.5(6.2,29.1)$ & 0.16 \\
\hline
\end{tabular}

Measurements made during AECOPD and during a stable state at least 8-weeks after exacerbation. Data presented as mean \pm SD or median (IQR)

$A E C O P D$ acute exacerbation of chronic obstructive pulmonary disease; IL-6 interleukin-6 

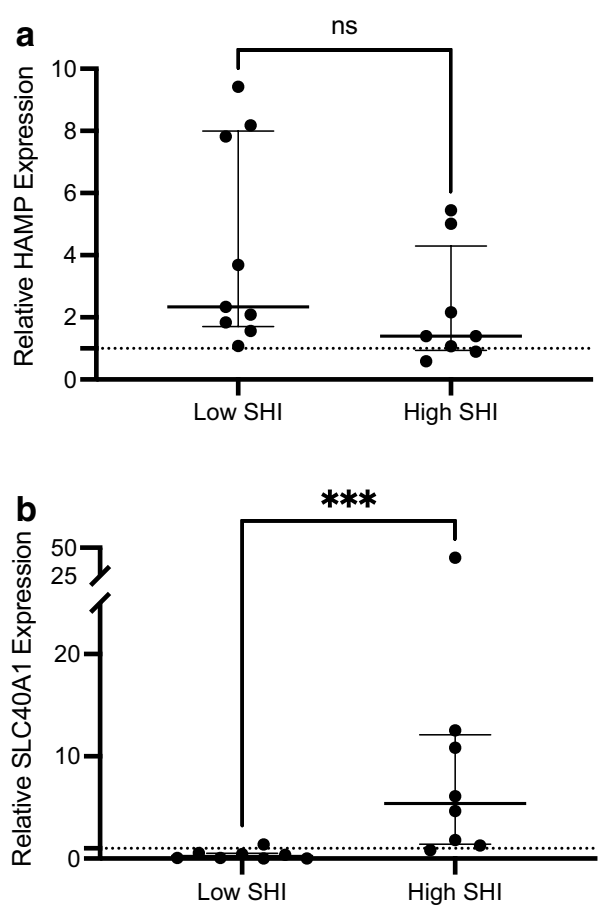

Fig. 2 a Relative gene expression of hepcidin in COPD patients based on stable sputum macrophage iron content. Data shown as median (IQR). HAMP hepcidin antimicrobial peptide; SHI sputum hemosiderin index. $\mathbf{b}$ Relative gene expression of ferroportin in COPD patients based on stable sputum macrophage iron content. Data shown as median (IQR). SLC40A1, solute carrier family 40 member 1; SHI sputum hemosiderin index. ${ }^{* * *} p<0.001$

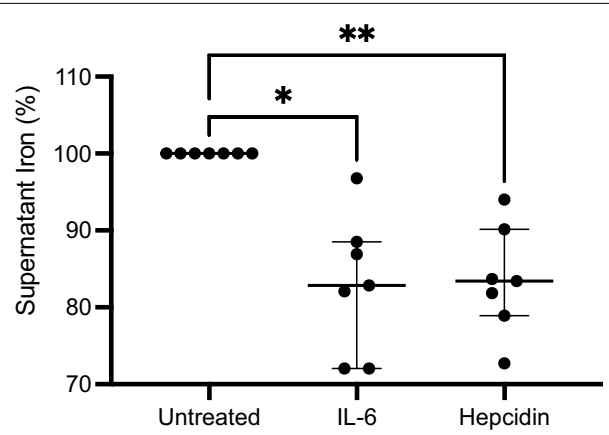

Fig. 3 Reduction in supernatant iron for sputum macrophage experiments. $N=7$. Data shown as median (IQR). IL-6 interleukin-6. ${ }^{*} p<0.05 ;{ }^{* *} p<0.01$

$2.00[0.671,2.99] \mu \mathrm{M})$. Subculturing with IL-6 and hepcidin together led to a statistically significant increase in TDM hemosiderin index compared to control (data not shown, $\mathrm{p}<0.05$ ). IL-6, hepcidin, and hi-HI subculture resulted in a decrease in supernatant iron concentration compared to control (data not shown, $\mathrm{p}<0.01$ ).

\section{Macrophage iron and susceptibility to infection}

In experiments with SM isolated from individuals from the COPD cohort, there was a near-significant correlation between SHI and the growth rate of H.influenzae at $0.5 \mathrm{~h}(\mathrm{r}=0.60, \mathrm{p}=0.075$, Spearman correlation; see Additional file 7: Fig. S3). As an exploratory condition, three participants had bacterial growth measured in the presence of the chelator Deferoxamine at $100 \mathrm{nM}$ (Abcam $^{\mathrm{TM}}$, Cambridge, UK), which demonstrated reduced growth of H.influenzae compared to control (median $-128[-237,-96] \%, \mathrm{p}=0.25$, Wilcoxon matched-pairs signed rank test; data not shown).

TDMs loaded with iron demonstrated a significant reduction in bacterial uptake compared to untreated cells for both H.influenzae (median - 28.3 $[-37.9,-15.5] \%, \mathrm{p}=0.002$, Mann-Whitney test) and S.pneumoniae (median $-32.5[-50.6,-12.0] \%$, $\mathrm{p}=0.0006$, Mann-Whitney test; data not shown). Evaluation of further time-points did not demonstrate differences in bactericidal capacity.

\section{Sputum hemosiderin index as a predictor of infectious AECOPD}

Amongst index admissions, 32 were secondary to infection while 17 were non-infectious (criteria as defined in Methods). Infective exacerbations were confirmed by bacterial culture in $10(31 \%)$, by RV-PCR (without positive bacterial culture) in $10(31 \%)$, and by differential and cell count alone in 12 (38\%). There were 73 readmissions for AECOPD during the follow-up period. Analysing by patient revealed that there was a median of $1(0,2)$, or mean of $1.49 \pm 1.56$ readmissions. A corresponding sputum sample and RV-PCR were collected in 40 (55\%) and 52 (71.2\%) of these episodes, respectively, of which 33 (45.2\%) were proven to be infective exacerbations. For readmissions, infective exacerbation were confirmed by bacterial culture in 15 (45.5\%), by RVPCR (without positive bacterial culture) in 5 (15.1\%), and by differential and cell count alone in 13 (39.4\%).

Negative binomial regression was performed for SHI at AECOPD and during a clinically stable period, accounting for covariates of $\mathrm{FEV}_{1}$ \% Predicted, the number of admissions for AECOPD in the last 1-year, age, sex, and inhaled corticosteroid use. SHI while clinically stable was a significant predictor of infective exacerbations $(\beta=0.035, \mathrm{p}=0.035)$, and $\mathrm{FEV}_{1} \%$ Predicted was borderline significant $(\beta=-0.049, \mathrm{p}=0.051$; Table 3$)$. When serum IL- 6 was added to the model, SHI was borderline predictive $(\beta=0.038, p=0.05$; see Additional file 8: Table S3). 
Table 3 Negative binomial regression model

\begin{tabular}{lclllll}
\hline Coefficients & Estimate & Standard Error & $\mathbf{p}$-value & $\mathbf{9 5 \%} \mathbf{C l}$ & Rate ratio & $\mathbf{9 5 \%} \mathbf{C l}$ \\
\hline Intercept & 0.115 & 2.603 & 0.965 & -4.987 to 5.217 & 1.122 & 0.007 to 184.361 \\
Admissions in last year & 0.098 & 0.213 & 0.646 & -0.320 to 0.516 & 1.103 & 0.726 to 1.675 \\
FEV ${ }_{1}$ \%redicted & -0.049 & 0.025 & 0.051 & -0.099 to 0.000 & 0.952 & 0.906 to 1.000 \\
SHI at follow-up & 0.035 & 0.016 & 0.035 & 0.002 to 0.067 & 1.035 & 1.002 to 1.069 \\
Age & -0.008 & 0.045 & 0.860 & -0.097 to 0.081 & 0.992 & 0.908 to 1.084 \\
Sex & 0.417 & 0.620 & 0.502 & -0.799 to 1.633 & 1.517 & 0.450 to 5.119 \\
ICS use & 0.862 & 1.377 & 0.531 & -1.837 to 3.561 & 2.368 & 0.159 to 35.187 \\
\hline
\end{tabular}

FEV ${ }_{1}$ forced expiratory volume in 1-s, SHI sputum hemosiderin index, ICS inhaled corticosteroid

\section{Discussion}

In this study, experiments investigating the mechanisms of pulmonary iron sequestration and hypothesized macrophage dysfunction were paired with a prospective COPD cohort to determine if there is a coherent pathophysiologic mechanism by which increased sputum macrophage iron could predispose to infective AECOPD.

Regarding the mechanisms of pulmonary macrophage iron sequestration, there appears to be a role for both IL-6 and hepcidin. In contrast to tissue macrophages, we demonstrated that IL- 6 caused pulmonary iron sequestration independent of hepcidin. This role for IL- 6 was corroborated by the prospective cohort. Though gene expression studies provide evidence that the hepcidinferroportin axis is available within sputum macrophages, high iron levels within these cells in the presence of increased ferroportin gene expression would suggest that hepcidin plays a role in iron sequestration, but that this pathway is compensatory, rather than the main driver. Cigarette smoke is considered a source of pulmonary iron, but we were not able to demonstrate a consistent association between cigarette smoke and sputum iron levels. The only other study examining pulmonary iron sequestration focused on airway epithelial cells and performed limited macrophage experiments (where only hepcidin was studied). Contrary to our findings, they found that exogeneous hepcidin did not cause iron sequestration in pulmonary macrophages [23], which may be related to our experiments using a higher concentration of hepcidin corresponding with systemic inflammation. The roles of IL- 6 and ferroportin on pulmonary macrophage iron sequestration have not been previously been studied in human cells.

In-vitro experiments of TDM and SM from COPD patients were used to test the effect of macrophage ironloading on cellular immune function. Iron-loaded SM demonstrated increased bacterial growth rates. Due to low cell yield, an issue inherent when working with SM isolated by plastic adherence, as well as a lack of a realtime iron quantification required to have an independent control group, we were not able to determine if this increased growth rate in SM was related to an impairment of bacterial uptake or killing. However, the reduced bacterial uptake seen in TDM experiments suggests that this mechanism is more prominent. Other studies examining excess iron in macrophages are limited to cell-line or murine macrophages, and experimental conditions manipulating hepcidin rather than iron itself [24, 25]. A single previous study demonstrated a reduction in cell-line macrophage bacterial killing rate [16]. To our knowledge, this is the first study to assess the effect of iron content on human pulmonary macrophage immune dysfunction.

Finally, with a prospective COPD cohort, we demonstrated that sputum macrophage iron content shortly after exacerbation is a predictor of future infective AECOPD. Pulmonary iron varied between patients and clinical status (exacerbation versus stable), but did not appear to be related to smoking status. During AECOPD, free sputum iron increased, and after the exacerbation resolved, free sputum iron decreased with a concomitant increase in SHI, suggestive of active pulmonary macrophage iron sequestration. It is plausible that in those individuals with an increase in IL-6 associated with AECOPD, the iron sequestration process initiates and ultimately leads to elevated SHI detected after the exacerbation event. Our findings would suggest that elevated SM iron in these individuals impairs macrophage immune function and ultimately predisposes to infective AECOPD. Our group had previously described that SHI was predictive of infective AECOPD [26]. Despite that previous study being retrospective and using a less robust definition of infective exacerbation (based on selfreported antibiotic use), there was a similar rate ratio for SHI (for every $1 \%$ increment, there was a corresponding $3.5 \%$ increase in infective exacerbations). A recent observational study demonstrated higher bronchoalveolar lavage fluid iron in those who subsequently developed exacerbation compared those who did not [14]. Our study differed in that it examined patients with more 
severe COPD, and measured our outcome prospectively rather than retrospectively.

The first limitation of this study relates to a limited sample size of various sputum macrophage experiments, and a yield of sputum macrophages in the experiments that prevented confirmation of intracellular iron accumulation and gene expression studies. Unfortunately, this was unavoidable due to the nature of the macrophage isolation techniques. We feel that coupling this data with data from a prospective COPD cohort presented a convergent framework of pulmonary iron sequestration and predisposition to infection. There were some inconsistent findings between macrophage experiments and the prospective cohort. While IL-6 led to iron sequestration in macrophage experiments, sputum IL-6 was not significantly higher after exacerbation. However, we were able to demonstrate a correlation between SHI and sputum IL-6 (Fig. S1a), and there was also a trend towards higher sputum IL-6 post-AECOPD. Secondly, gene expression studies were conducted on a heterogeneous population of sputum cells rather than macrophages alone. However, all samples contained 1-3 million macrophages per gram of sputum, and aside from HAMP being expressed in neutrophils [27], neither HAMP or SLC40A1 are known to be expressed in other cell types found in sputum. Thirdly, exacerbations of moderate severity, that is not requiring emergency room visit or hospitalization, were not measured and certainly could have been of infectious etiology. However, we chose to focus on severe exacerbations as they are more reliably captured (as opposed to self-report), and it was more feasible to characterize these episodes by collecting adequate sputum samples in this context. Using this approach, we were able to accurately characterize participants' exacerbations with RVPCR and sputum cytometry, rather than rely only on a history of antibiotic use. Of note, the rate of hospitalizations due to COPD was high as compared to large population-based studies, highlighting that our cohort was particularly prone to exacerbations. Lastly, our focus was on macrophage iron sequestration, and thus we did not measure iron bound to iron-binding proteins such as ferritin or lipocalin-2.

In summary, this study demonstrates that excess airway macrophage iron occurs in a subset of patients with COPD, and when present prospectively predicts infectious exacerbation. Furthermore, we elucidate a plausible mechanism by which this may occur involving IL-6, and iron-related immune dysfunction of macrophages. Further research is required to fully understand the mechanisms of pulmonary iron sequestration in health and disease, and to determine if airway iron could be a target for therapeutic intervention.

\section{Abbreviations}

$\triangle C$ t: Difference in cycle threshold; AECOPD: Acute exacerbation of chronic obstructive pulmonary disease; CDNA: Complementary deoxyribonucleic acid; CFU: Colony forming unit; COPD: Chronic obstructive pulmonary disease; ELISA: Enzyme linked immunosorbent assay; FEV1: Forced expiratory volume in $1 \mathrm{~s}$; FVC: Forced vital capacity; HAMP: Hepcidin antimicrobial peptide; hi-HI: Heat-inactivated Haemophilus influenzae; ICP-MS: Inductively-coupled mass spectrometry; IL-6: Interleukin-6; RT-qPCR: Real-time quantitative polymerase chain reaction; $\mathrm{RV}-\mathrm{PCR}$ : Respiratory virus polymerase chain reaction; $\mathrm{SHI}$ : Sputum hemosiderin index; TDM: THP1-derived macrophages; THP1:Tamm Horsfall Protein 1.

\section{Supplementary Information}

The online version contains supplementary material available at https://doi. org/10.1186/s12931-022-01929-7.

Additional file 1: Supplementary Methods. A supplement to the Methods section.

Additional file 2: Table S1. Systemic iron and echocardiographic parameters of COPD clinical cohort.

Additional file 3: Figure S1a. Linear regression of sputum supernatant interleukin-6 (by ELISA) and sputum hemosiderin index.

Additional file 4: Figure S1b. Linear regression of serum interleukin-6 (by ELISA) and sputum hemosiderin index.

Additional file 5: Table S2: Characteristics of RT-qPCR cohorts.

Additional file 6: Figure S2. Intracellular iron content of cell-line derived macrophages after 24-hour incubation with various conditions.

Additional file 7: Figure S3. Linear regression of sputum hemosiderin index and growth rate of $H$. influenzae.

Additional file 8: Table S3: Negative binomial regression model.

\section{Acknowledgements}

The authors would like to thank Drs. Gerard Cox and Martin Stampfli for being part of the Corresponding Author's MSc supervisory committee.

\section{Authors' contributions}

TH designed the study, collected and analysed the data, and wrote and edited the manuscript. MN and MM designed the study, collected and analysed the data, and wrote and edited the manuscript. GN, MS, and JM designed the study, collected data, and edited the manuscript. KR, MN, CH, AB, NL collected data and edited the manuscript. PN designed the study, analysed the data, and wrote and edited the manuscript. All authors read and approved the final manuscript.

Funding

N/A.

Availability of data and materials

The datasets used and/or analysed during the current study are available from the corresponding author on reasonable request.

\section{Declarations}

\section{Ethics approval and consent to participate}

Informed consent was obtained from all subjects. The study was approved by the Hamilton Integrated Research Ethics Board (Project \#1281).

\section{Consent for publication}

N/A.

\section{Competing interests}

TH reports grants and non-financial support from Fisher and Paykel healthcare, and personal fees from Sanofi, outside the submitted work, and is supported by the McMaster Department of Medicine Early Career Award. MM is 
supported by an early career investigator award from CIHR, Canadian Asthma Allergy and Immunology Foundation, and reports grants from CIHR, Methapharm Specialty Pharmaceuticals, and personal fees from Astra Zeneca and GlaxoSmithKline, outside the submitted work. PN reports grants and personal fees from AZ, grants from Novartis, grants and personal fees from Teva, grants from Sanofi, grants and personal fees from Roche, personal fees from Novartis, personal fees from Merck, personal fees from Equillium, grants from Foresee, outside the submitted work, and is supported by the Frederick E Hargreave Teva Innovation Chair in Airway Diseases. The other authors report no conflict of interest.

\section{Author details}

${ }^{1}$ Department of Medicine, McMaster University, Hamilton, Canada. ${ }^{2}$ Firestone Institute for Respiratory Health, St. Joseph's Healthcare Hamilton, 50 Charlton Avenue East, Hamilton, ON L8N 4A6, Canada. ${ }^{3}$ Department of Pathology and Laboratory Medicine, Western University, London, Canada. ${ }^{4}$ St. Joseph's Healthcare Hamilton, Hamilton, Canada. ${ }^{5}$ Department of Pathology and Molecular Medicine, McMaster University, Hamilton, Canada.

Received: 14 September 2021 Accepted: 4 January 2022

Published online: 12 January 2022

\section{References}

1. O'Donnell DE, Aaron SD, Bourbeau J, Hernandez P, Marciniuk DD, Balter $M$, et al. Canadian Thoracic Society recommendations for management of chronic obstructive pulmonary disease-2007 update. Can Respir J. 2007:14:5B-32B

2. Vogelmeier CF, Criner GJ, Martinez FJ, Anzueto A, Barnes PJ, Bourbeau J, et al. Global strategy for the diagnosis, management, and prevention of chronic obstructive lung disease 2017 report. Am J Respir Crit Care Med. 2017:195:557-82.

3. Connors AF, Dawson NV, Thomas C, Harrell FE, Desbiens N, Fulkerson WJ, et al. Outcomes following acute exacerbation of severe chronic obstructive lung disease. Am J Respir Crit Care Med. 1996;154:959-67.

4. Dickson RP, Martinez FJ, Huffnagle GB. The role of the microbiome in exacerbations of chronic lung diseases. Lancet. 2014;384(9944):691-702.

5. Reid DW, Anderson GJ, Lamont IL. Role of lung iron in determining the bacterial and host struggle in cystic fibrosis. Am J Physiol Lung Cell Mol Physiol. 2009;297(5):L795-802.

6. Nairz M, Schroll A, Demetz E, Tancevski I, Theurl I, Weiss G. "Ride on the ferrous wheel"-The cycle of iron in macrophages in health and disease. Immunobiology. 2015;220(2):280-94.

7. Winter WE, Bazydlo LAL, Harris NS. The Molecular biology of human iron metabolism. Lab Med. 2014:45(2):92-102.

8. Nguyen NB. Hepcidin expression and iron transport in alveolar macrophages. Am J Physiol Lung Cell Mol Physiol. 2006;291(3):L417-25.

9. Deschemin J-C, Mathieu JRR, Zumerle S, Peyssonnaux C, Vaulont S. pulmonary iron homeostasis in hepcidin knockout mice. Front Physiol. 2017:8:359-414

10. Pelusi S, Girelli D, Rametta R, Campostrini N, Alfieri C, Traglia M, et al. The A736V TMPRSS6 polymorphism influences hepcidin and iron metabolism in chronic hemodialysis patients: TMPRSS6 and hepcidin in hemodialysis. BMC Nephrol. 2013;14(1):1-1.

11. Ali MK, Kim RY, Brown AC, Donovan C, Vanka KS, Mayall JR, et al. Critical role for iron accumulation in the pathogenesis of fibrotic lung disease. $J$ Pathol. 2020;251(1):49-62.

12. Ali MK, Kim RY, Brown AC, Mayall JR, Karim R, Pinkerton JW, et al. Crucial role for lung iron level and regulation in the pathogenesis and severity of asthma. Eur Respir J. 2020;55(4):1901340.

13. Philippot Q, Deslée G, Adair-KirkTL, Woods JC, Byers D, Conradi S, et al. Increased iron sequestration in alveolar macrophages in chronic obstructive pulmonary disease. PLoS ONE. 2014;9(5):e96285.

14. Zhang WZ, Oromendia C, Kikkers SA, Butler JJ, Beirne SOX, Kim K, et al. Increased airway iron parameters and risk for exacerbation in COPD: an analysis from SPIROMICS. Sci Rep. 2020;10:1-13.

15. Cloonan SM, Glass K, Laucho-Contreras ME, Bhashyam AR, Cervo M, Pabón MA, et al. Mitochondrial iron chelation ameliorates cigarette smoke-induced bronchitis and emphysema in mice. Nat Med. 2016:22(2):163-74.
16. Kao J-K, Wang S-C, Ho L-W, Huang S-W, Chang S-H, Yang R-C, et al. Chronic iron overload results in impaired bacterial killing of THP-1 derived macrophage through the inhibition of lysosomal acidification. PLoS ONE. 2016;11(5):e0156713.

17. Zhou H, Kobzik L. Effect of concentrated ambient particles on macrophage phagocytosis and killing of Streptococcus pneumoniae. Am J Respir Cell Mol Biol. 2007;36(4):460-5.

18. Bedi P, Chalmers JD, Goeminne PC, Mai C, Saravanamuthu P, Velu PP, et al. The BRICS (Bronchiectasis Radiologically Indexed CT Score): a multicenter study score for use in idiopathic and postinfective bronchiectasis. Chest. 2018;153(5):1177-86

19. Pizzichini E, Pizzichini MMM, Efthimiadis AE, Evans S, Morris MM, Squillace $D$, et al. Indices of airway inflammation in induced sputum: reproducibility and validity of cell and fluid-phase measurements. Am J Respir Crit Care Med. 1996;154:308-17.

20. Kim LH-Y, Plaza K, Thomas SR, Draijer C, Radford K, Peters-Golden M, et al. Endogenous peroxidases in sputum interfere with horse-radish peroxidase-based ELISAs. J Immunol Methods. 2018;454:76-9.

21. Anthonisen NR, Manfreda J, Warren CP, Hershfield ES, Harding GK, Nelson NA. Antibiotic therapy in exacerbations of chronic obstructive pulmonary disease. Ann Int Med. 1987;106(2):196-204.

22. Sadatsafavi M, Sin DD, Zafari Z, Criner G, Connett JE, Lazarus S, et al. The Association between rate and severity of exacerbations in chronic obstructive pulmonary disease: an application of a joint frailty-logistic model. Am J Epidemiol. 2016;184(9):681-9.

23. Frazier MD, Mamo LB, Ghio AJ, Turi JL. Hepcidin expression in human airway epithelial cells is regulated by interferon- $\gamma$. Respir Res. 2011;12(1):100.

24. Lim D, Kim KS, Jeong J-H, Marques O, Kim H-J, Song M, et al. The hepcidin-ferroportin axis controls the iron content of Salmonella-containing vacuoles in macrophages. Nat Commun. 2018;9(1):1-12.

25. Paradkar PN, De Domenico I, Durchfort N, Zohn I, Kaplan J, Ward DM. Iron depletion limits intracellular bacterial growth in macrophages. Blood. 2008;112(3):866-74

26. Mohan S, Ho T, Kjarsgaard M, Radford K, Borhan ASM, Thabane L, et al. Hemosiderin in sputum macrophages may predict infective exacerbations of chronic obstructive pulmonary disease: a retrospective observational study. BMC Pulm Med. 2017;17(1):60.

27. Peyssonnaux C. TLR4-dependent hepcidin expression by myeloid cells in response to bacterial pathogens. Blood. 2006;107(9):3727-32

\section{Publisher's Note}

Springer Nature remains neutral with regard to jurisdictional claims in published maps and institutional affiliations.

Ready to submit your research? Choose BMC and benefit from

- fast, convenient online submission

- thorough peer review by experienced researchers in your field

- rapid publication on acceptance

- support for research data, including large and complex data types

- gold Open Access which fosters wider collaboration and increased citations

- maximum visibility for your research: over 100M website views per year

At BMC, research is always in progress.

Learn more biomedcentral.com/submissions 